\title{
Article
}

\section{ICONS II: Identifying Continence OptioNs after Stroke randomised controlled trial}

Thomas, Lois Helene, Roffe, Christine, Booth, Joanne, Chapple, Christopher, Watkins, Caroline Leigh, Roe, Brenda, Sutton, Chris J, Hollingsworth, Bruce, Mateus, Ceu, Britt, David, Panton, Cliff and Bennett, Kina

Available at http://clok.uclan.ac.uk/22536/

Thomas, Lois Helene ORCID: 0000-0001-5218-6546, Roffe, Christine, Booth, Joanne, Chapple, Christopher, Watkins, Caroline Leigh ORCID: 0000-00029403-3772, Roe, Brenda, Sutton, Chris J ORCID: 0000-0002-6406-1318, Hollingsworth, Bruce, Mateus, Ceu et al (2018) ICONS II: Identifying Continence OptioNs after Stroke randomised controlled trial. British Journal of Neuroscience Nursing, 14 (Sup2). S24-S25. ISSN 1747-0307

It is advisable to refer to the publisher's version if you intend to cite from the work. 10.12968/bjnn.2018.14.sup2.s24

For more information about UCLan's research in this area go to http://www.uclan.ac.uk/researchgroups/ and search for <name of research Group>.

For information about Research generally at UCLan please go to http://www.uclan.ac.uk/research/

All outputs in CLoK are protected by Intellectual Property Rights law, including Copyright law. Copyright, IPR and Moral Rights for the works on this site are retained by the individual authors and/or other copyright owners. Terms and conditions for use of this material are defined in the policies page. 


\section{Short article for Journal of Neuroscience Nursing}

ICONS II: Identifying Continence OptioNs after Stroke randomised controlled trial.

Thomas LH, Roffe C, Booth J, Chapple C, Watkins CL, Roe B, Sutton CJ, Hollingsworth B, Mateus C, Britt $\mathrm{D}$, Panton $\mathrm{C}$ and Bennett $\mathrm{K}$

\section{Background}

Stroke is one of the two greatest causes of death worldwide, accounting for $10 \%$ of deaths in 2010 . Globally, there were 16.9 million people with a first stroke and 33 million stroke survivors in 2010 [1]. In the UK, up to 95,000 people survive a stroke per annum [1]. Incidence is unlikely to decline given the ageing population, and prevalence continues to rise.

Urinary incontinence (UI) is defined as the complaint of any involuntary leakage of urine [2]. UI affects around half of stroke survivors in the acute phase $[3,4]$. As many as $44 \%$ and $38 \%$ of stroke survivors remain incontinent at 3 months and 1 year respectively [5]. UI often presents as a new problem after stroke or, if pre-existing, worsens significantly, adding to the disability and helplessness caused by neurological deficits [6].

The more severe the stroke, the greater the likelihood of UI [7]; other factors include older age or cognitive impairment [8]. Urge incontinence (involuntary leakage immediately following, or concurrent with, an urgent sensation of needing to void is the most common type after stroke [9] and is generally the result of detrusor over-activity. Stroke patients with UI have considerably worse outcomes: there is a clear association between $\mathrm{Ul}$ after stroke and death, disability and an increased likelihood of discharge into residential care $[7,10,11]$.

$\mathrm{UI}$ is distressing for individuals and families and depression is twice as common in stroke survivors who are incontinent $[12,13]$. Negative social consequences for survivors and carers cannot be ignored: both may become isolated and marginalised [14]. Continuing incontinence is associated with poor outcome in both stroke survivors and carers [3, 15-17].

It is important to study $\mathrm{UI}$ in this population as symptoms are more severe and have more of an effect compared with other groups of people [6]. Furthermore, associated stroke impairments compound difficulties with bladder control with motor, visual or speech problems making the task of accessing toilet facilities a challenge [18].

Incontinence is often poorly managed, even by specialist teams working on recognised stroke units [19]. Failure to address the problem may be because of lack of knowledge of the mechanisms of UI or emphasis on management in primary care [20]. The opportunity for early intervention to enhance natural recovery in secondary care is therefore being missed.

Furthermore, despite clinical guidelines stating indwelling urethral catheters (IUCS) should only be used to relieve retention [21], there is over-reliance on catheterisation as a management strategy for UI in stroke units, especially in the acute phase [19,22]. This puts patients at risk of IUC-associated urinary tract infection and its consequences [23-26], including increased morbidity, mortality and resource use [24, 27, 28]. In our ICONS: Identifying Continence OptioNs after Stroke feasibility trial, $48 \%$ of patients in intervention arms were catheterised in the acute phase [29]. Urinary tract infection and antibiotic use are considerably higher in patients with IUCS, with increasing risk of infection associated with later removal [30]. 
The update of our Cochrane review 'Treatment of urinary incontinence after stroke in adults' has revealed several new studies [31-34], however the conclusion, that data from the available trials are insufficient to guide continence care, is unlikely to change without a definitive trial. We have received funding for a trial from the UK National Institute for Health Research Health Technology Assessment Programme to address this clear gap in the evidence base.

\section{The ICONS II trial}

The ICONS II trial will build on our recent feasibility trial [29, 35] and rigorously test a programme designed to assess and treat $\mathrm{UI}$ after stroke in hospital. It will answer the research question "Is a systematic voiding programme a clinically effective and cost effective treatment for urinary incontinence (UI) in patients with urinary incontinence after stroke in secondary care?"

ICONS II is a pragmatic, multicentre, randomised parallel group trial to compare the effectiveness of the systematic voiding programme $(n=512)$ with usual care $(n=512)$ in reducing the severity of $\mathrm{UI}$ in patients with stroke and $\mathrm{UI}$ in secondary care. The trial includes a mixed methods process evaluation investigating fidelity to the intervention and usual care, and an economic evaluation of the systematic voiding programme compared with usual care.

We are currently recruiting stroke units in England and Wales to participate in the trial, and will begin recruiting participants in July 2018.

For further information about the trial, please contact Dr Lois Thomas, Ihthomas@uclan.ac.uk, +44(0) 1772893643.

\section{2 words}

Funding acknowledgement: This research was funded by the NIHR HTA Programme (16/111/31)

Department of Health disclaimer: The views expressed are those of the authors and not necessarily those of the NHS, the NIHR or the Department of Health 


\section{References}

1. Feigin, V.L., et al., Global and regional burden of stroke during 1990-2010: findings from the Global Burden of Disease Study 2010. Lancet, 2014. 383(9913): p. 245-54.

2. Abrams, P., et al., The standardisation of terminology of lower urinary tract function: report from the Standardisation Sub-committee of the International Continence Society. Neurourol.Urodyn., 2002. 21(2): p. 167-178.

3. Kolominsky-Rabas, P.L., et al., Impact of urinary incontinence after stroke: results from a prospective population-based stroke register. Neurourol.Urodyn., 2003. 22(4): p. 322-327.

4. Tuong, N.E., A.P. Klausner, and L.J. Hampton, A review of post-stroke urinary incontinence. Can J Urol, 2016. 23(3): p. 8265-70.

5. Williams, M.P., et al., Urinary symptoms and natural history of urinary continence after firstever stroke--a longitudinal population-based study. Age Ageing, 2012. 41(3): p. 371-376.

6. Brittain, K.R., et al., Prevalence and impact of urinary symptoms among community-dwelling stroke survivors. Stroke, 2000. 31(4): p. 886-891.

7. Brittain, K.R., S.M. Peet, and C.M. Castleden, Stroke and incontinence. Stroke, 1998. 29(2): p. 524-528.

8. Barrett, J.A., Bladder and bowel problems after stroke. Reviews in Clinical Gerontology, 2002. 12: p. 253-267.

9. Pettersen, R., R. Stien, and T.B. Wyller, Post-stroke urinary incontinence with impaired awareness of the need to void: clinical and urodynamic features. BJU.Int., 2007. 99(5): p. 1073-1077.

10. Hankey, G.J., et al., Five-year survival after first-ever stroke and related prognostic factors in the Perth Community Stroke Study. Stroke, 2000. 31(9): p. 2080-6.

11. Nakayama, H., et al., Prevalence and risk factors of incontinence after stroke. The Copenhagen Stroke Study. Stroke, 1997. 28(1): p. 58-62.

12. Brittain, K.R., Urinary symptoms and depression in stroke survivors. Age \& Ageing, 1998. 27 (Suppl. 1): p. 116-117.

13. Limampai, P., W. Wongsrithep, and V. Kuptniratsaikul, Depression after stroke at 12-month follow-up: a multicenter study. Int J Neurosci, 2017. 127(10): p. 887-892.

14. Brittain, K.R. and C. Shaw, The social consequences of living with and dealing with incontinence--a carers perspective. Soc.Sci.Med., 2007. 65(6): p. 1274-1283.

15. Arkan, G., A. Beser, and V. Ozturk, Experiences Related to Urinary Incontinence of Stroke Patients: A Qualitative Descriptive Study. J Neurosci Nurs, 2018. 50(1): p. 42-47.

16. Pettersen, R. and T.B. Wyller, Prognostic significance of micturition disturbances after acute stroke. J Am Geriatr Soc, 2006. 54(12): p. 1878-84.

17. Tseng, C.N., et al., A Qualitative Study of Family Caregiver Experiences of Managing Incontinence in Stroke Survivors. PLoS One, 2015. 10(6): p. e0129540.

18. Brittain, K.R., et al., Prevalence and management of urinary incontinence in stroke survivors. Age Ageing, 1999. 28(6): p. 509-511.

19. Booth, J., et al., Rehabilitation nurses practices in relation to urinary incontinence following stroke: a cross-cultural comparison. J.Clin.Nurs., 2009. 18(7): p. 1049-1058.

20. Thomas, L.H., et al., Treatment of urinary incontinence after stroke in adults. Cochrane.Database.Syst.Rev., 2008(1): p. CD004462.

21. Intercollegiate Stroke Working Party, National clinical guideline for stroke. 2016, Royal College of Physicians: London.

22. Cowey, E., et al., Urinary catheterization in acute stroke: clinical realities. A mixed methods study. Clin Rehabil, 2012. 26(5): p. 470-9.

23. Poisson, S.N., S.C. Johnston, and S.A. Josephson, Urinary tract infections complicating stroke: mechanisms, consequences, and possible solutions. Stroke, 2010. 41(4): p. e180-4. 
24. Kwan, J. and P. Hand, Infection after acute stroke is associated with poor short-term outcome. Acta Neurol Scand, 2007. 115(5): p. 331-8.

25. Roth, E.J., et al., Incidence of and risk factors for medical complications during stroke rehabilitation. Stroke, 2001. 32(2): p. 523-9.

26. Stott, D.J., et al., Urinary tract infection after stroke. QJM, 2009. 102(4): p. 243-9.

27. Aslanyan, S., et al., Pneumonia and urinary tract infection after acute ischaemic stroke: a tertiary analysis of the GAIN International trial. Eur J Neurol, 2004. 11(1): p. 49-53.

28. Roth, E.J., et al., Stroke rehabilitation: indwelling urinary catheters, enteral feeding tubes, and tracheostomies are associated with resource use and functional outcomes. Stroke, 2002. 33(7): p. 1845-50.

29. Thomas, L.H., et al., ICONS: Identifying Continence OptioNs after Stroke: An evidence synthesis, case study and exploratory cluster randomised controlled trial of the introduction of a systematic voiding programme for patients with urinary incontinence after stroke in secondary care. Programme Grants for Applied Research, 2015. 3(1).

30. Griffiths, R. and R. Fernandez, Strategies for the removal of short-term indwelling urethral catheters in adults. Cochrane Database Syst Rev, 2007(2): p. CD004011.

31. Guo, Z.F., et al., Transcutaneous electrical nerve stimulation in the treatment of patients with poststroke urinary incontinence. Clin Interv Aging, 2014. 9: p. 851-6.

32. Liu, Y., L. Liu, and X. Wang, Electroacupuncture at points Baliao and Huiyang (BL35) for poststroke detrusor overactivity. Neural Regen Res, 2013. 8(18): p. 1663-72.

33. Shin, D.C., et al., Pelvic floor muscle training for urinary incontinence in female stroke patients: a randomized, controlled and blinded trial. Clinical Rehabilitation, 2016. 30(3): p. 259-267.

34. Tibaek, S., et al., Is Pelvic Floor Muscle Training Effective for Men With Poststroke Lower Urinary Tract Symptoms? A Single-Blinded Randomized, Controlled Trial. Am J Mens Health, 2015.

35. Thomas, L.H., et al., Identifying continence options after stroke (ICONS): a cluster randomised controlled feasibility trial. Trials, 2014. 15(1): p. 509. 